\title{
Cross-cultural Competence and Its Development
}

\author{
Yanbin Qin \\ Department of Fundamental Courses, Zhenjiang Watercraft College, Zhenjiang, China \\ Email: qybzsx@tom.com
}

\begin{abstract}
Cross-cultural competence is composed of three components, i.e. the sensitivity to cultural differences, tolerance towards cultural differences and flexibility in dealing with problems of cultural differences, which are from low to high in stratification. TEFL should improve the learners' cognitive competence and their competence in solving problems concerning cross-cultural differences.
\end{abstract}

Index Terms-communicative competence, cross-cultural communicative competence, cross-cultural competence

\section{INTRODUCTION}

In view of the important role of cultural differences in cross-cultural communicative competence, it is necessary to stimulate appropriately and effectively the development of the learners' cognitive competence and their competence to deal with difficult cases resulting from cross-cultural differences in the teaching English as a foreign language. The model of cross-cultural communicative competence is a supplement and development of the previous models of communicative competence. Since there are great differences in the comprehension of communicative competence, it is necessary to make a summary of the previous models of communicative competence.

Since Hymes advanced the concept and constitution of communicative competence in 1972, many scholars have put forward their different understanding of it one after another and constituted their own communicative competence models. Just take an influential concept of communicative competence as an example to illustrate that it is hard to have something in common concerning the understanding about its concept and its components. Communicative competence refers to the ability not only to apply the grammatical rules of a language in order to form grammatically correct sentences but also to know when and where to use these sentences and to whom. Communicative competence includes: a) knowledge of the grammar and vocabulary of the language; $b$ ) knowledge of rules of speaking (e. g. knowing how to begin and end conversations, knowing what topics may be talked about in different types of speech events, knowing which address forms should be used with different persons one speaks to and in different situations; $c$ ) knowing how to use and respond to different types of speech acts, such as requests, apologies, thanks, and invitations; d) knowing how to use language appropriately. When someone wishes to communicate with others, they must recognize the social setting, their relationship to the other person(s), and the types of language that can be used for a particular occasion. They must also be able to interpret written or spoken sentences within the total context in which they are used. For example, the English statement It's rather cold here could be a request, particularly to someone in a lower role relationship, to close a window or door or to turn on the heating (Hymes 1972, 1977; Coulthard 1985). Here only several influential models concerned will be discussed in brief in this paper.

\section{A. Communicative Competence Model by Canale \& Swain}

Canale \& Swain pointed out for the first time that communicative competence consists of three parts in 1980. Then in 1983 Canale developed it into four parts, that is, linguistic competence, sociolinguistic competence, discourse competence and strategic competence as shown in Figure 1.

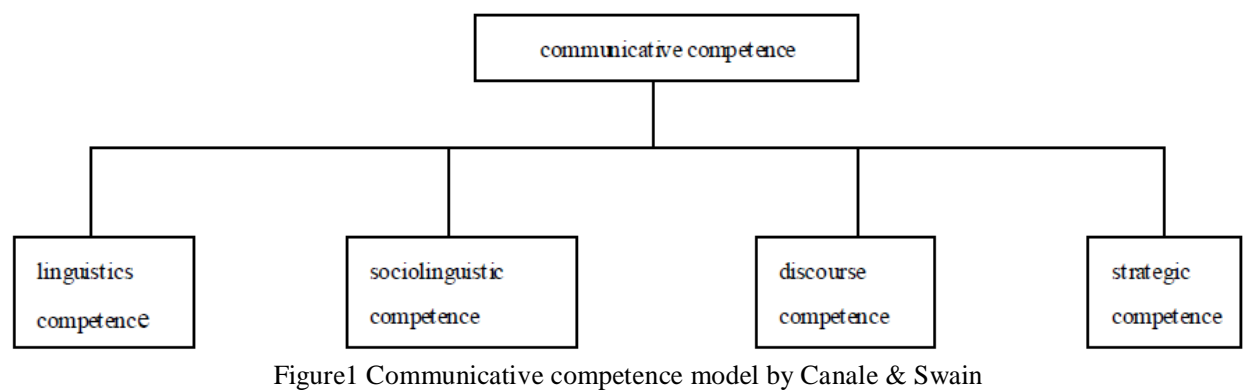

Linguistic competence refers to linguistic knowledge and skills while sociolinguistic competence refers to competence to choose appropriate way of expressing according to situational elements including communicative time, place, characters and so on. Discourse competence means the competence to plan and arrange discourse. Strategic competence means the competence to solve communicative difficulties; in other words, it means the participants' 
competence to take remedial measures when other competences can't meet the demands of communication.

\section{B. Communicative Competence Model by Bachman}

Based on the hypothesis advanced by Canale \& Swain, Bachman (1990) put forward a more complicated model of communicative competence which is composed of language competence, strategic competence and psycho-physical mechanism as shown in Figure 2. Here only the former two parts are covered.

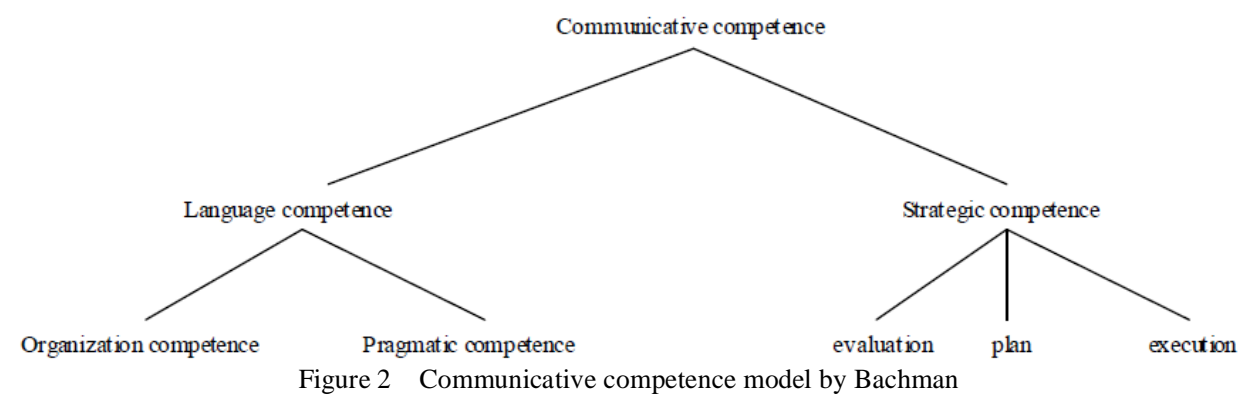

Language competence includes not only organization competence (grammar and discourse competence) but pragmatic competence as well, among which grammar competence means knowledge and skills in syntax, morphology, phonetics or spelling while the discourse competence refers to skills in textual level such as cohesion, coherence and organization. Pragmatic competence includes competence to express and practice language as well as competence to grasp rules of language usage. Strategic competence is subdivided into three parts: evaluation, plan and execution. To be more specific, it means how to make a correct evaluation of one's own and the partner's language and background knowledge in the course of verbal communication and then decide on the way to reach the aim of communication and finally fulfill the set plan through the relevant psycho-physical mechanism. Bachman's model of communicative competence is much more complicated than the previous ones, but its complexity is reflected only at micro-level. As a result, there are no essential differences from that of Canale \& Swain except the strategic competence as far as its macro-structure is concerned (Skehan, 1995).

\section{Communicative Competence Model by Li Xiaoju}

According to the models put forward by Canale \& Swain (1980) and Bachman (1990), Li Xiaoju advanced her own model in 1997. She holds that communicative competence is made up of three components, that is, linguistic competence, discourse competence and pragmatic competence as shown in Figure 3.

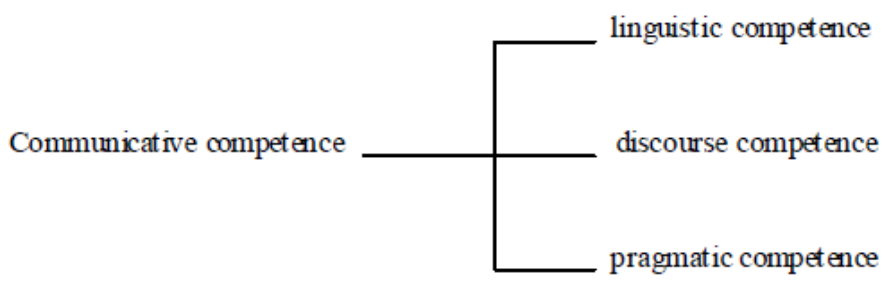

Figure 3 Communicative competence model by Li Xiaoju

Linguistic competence includes language knowledge and skills. Discourse competence refers to the competence to use language in context, while pragmatic competence in non-verbal situations. Non-verbal situations here refer to the time, place, status of participants, cultural background and etc. She holds that the three components connect, restrict and coordinate with each other.

\section{Comparison of the Three Models above}

There is no essential difference in contents among the first three parts of three models by comparison although they share different names as shown in Figure 4. It is interesting that they are totally different in the fourth part. Li Xiaoju's model is composed of only three parts; the models of Canale \& Swain and Bachman have the same name for the fourth, but there is no similarity in their connotation. Bachman's strategic competence refers to how the participants fulfill the communicative task through evaluation, plan and execution, whereas Canale \& Swain's the remedial competence in communication.

\begin{tabular}{|l|l|l|l|}
\hline & Canale \& Swain & Bachman & Li Xiaoju \\
\hline 1 & linguistic competence & language competence & linguistic competence \\
\hline 2 & discourse competence & organization competence & discourse competence \\
\hline 3 & sociolinguistic competence & pragmatic competence & pragmatic competence \\
\hline 4 & strategic competence(remedial competence) & strategic competence & \\
\hline
\end{tabular}

Figure 4 Comparison of the three models 
There is one shortcoming common in the three models except the similarities and differences mentioned above, namely, the competence of how to deal with cultural differences is not mentioned explicitly. It is well known that communication by means of foreign language always occurs between persons from different cultural background, namely cross-cultural communication. Cross-cultural communication is an exchange of ideas, information, etc. between persons from different cultural backgrounds. There are often more problems in cross-cultural communication than communication between people of the same cultural background. Each participant may interpret the other's speech according to his or her cultural conventions and expectations. If the cultural conventions of the speakers are widely different, misinterpretations and misunderstandings can easily arise, even resulting in a total breakdown of communication. This has been shown by research into real-life situations, such as job interviews, doctor-patient encounters and legal communication. Since English is an international language and the participants may come from English-speaking countries or non-English-speaking ones, they have utterly different cultural background. If the competence of how to deal with cultural differences is not included, it is difficult to improve the learners' level of foreign languages in an all-round way.

\section{The Model of Cross-Cultural Communicative Competence}

On the basis of analysis and comparison of the three models of communicative competence, Wen Qiufang (2000:9) advanced a model of cross-cultural communicative competence as shown in Figure 5. With the communicative competence put forward by the predecessors included, the cross-cultural competence is introduced into the new model, which is made up of three components, that is, sensitivity to cultural differences, tolerance towards cultural differences and flexibility in dealing with problems of cultural differences.

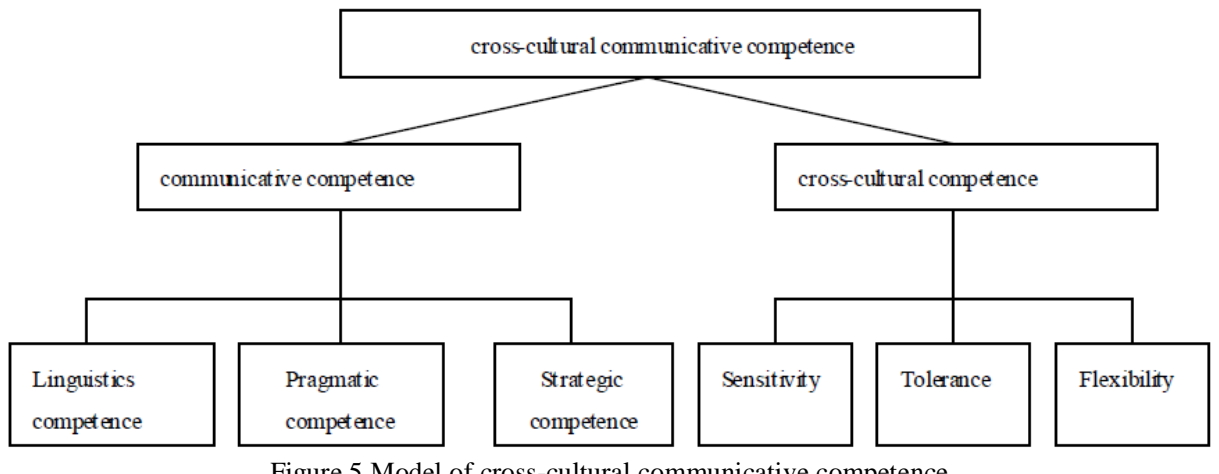

\section{A. Sensitivity to Cultural Differences}

Sensitivity to cultural differences means that in verbal communication participants not only know the surface cultural differences of the target language country but can easily identify the deep-seated differences of two sides as well. There is no need for them to have special training to distinguish the evident surface cultural differences (Levine, 1987). For example, when the Chinese come to the U.S.A., they will find Americans have different language and dietary habits from them. On the other hand, the deep-rooted cultural differences are not so easy to identify, which is due to the fact that the cultural difference in deep structure is much more abstract and is considered to be in the speaker's, writer's, hearer's or reader's mind. For example, the Westerners get information mainly from the language itself, while the Asians especially the Japanese and the Chinese from the situation, the speaker's expression, behavior and so on besides the language. As the popular Chinese idioms go, "We judge the drums by the sound and the words by the voice" and "We should have sharp eyes and keen ears", which mean that the Easterners are better at obtaining information in various ways.

Since the cultural difference in deep structure is hidden in people's behavior and thoughts and difficult to observe directly, it is even more necessary to develop the sensitivity to the cultural differences consciously. At the same time, the sensitivity is migratory, which means that it can go beyond the national boundaries and is not confined to the understanding of the target language country. As a result, with the exact sensitivity, the participants can easily find out the cultural differences in the deep structure between two sides.

One point to be stressed here is that sensitivity to cultural differences is different from knowledge of cultural differences. In fact, the development of student's competence to distinguish cultural differences must be made through the comparison of different countries. In other words, understanding and grasping the knowledge of foreign cultures is not an end but a means. No means, no end.

\section{B. Tolerance towards Cultural Differences}

The tolerance towards cultural differences refers to what kind of attitudes towards cultural differences, to be concrete, cultural differences are understandable, respectable or disgusting, disliked. Some people have a sense of cultural 
superiority, holding that cultures of other countries are backward compared to their own advanced one. The simple reason for it is that people are born to get edification from the native culture, so the ideas and system of values seem to be mixed with their own blood and work as an integral part of the whole body. Once it comes to conflict with the foreign culture, it will make such instinct response as incomprehension or dislike and what is more serious is disgusting attitude.

To develop tolerance towards cultural differences, we should clarify a correct concept first that culture is not inborn and just like language there is no such difference as so-called primitive or civilized culture. Armed with the proper concept, it is likely for us to show understanding and tolerance towards foreign culture in our behavior. On the other hand, tolerance is predicated on broad horizon. That is to say, the more understanding we have of the cultural differences between different countries, the more easily we tend to take an understandable and tolerant attitude toward them.

\section{Flexibility in Dealing with Problems of Cultural Differences}

Flexibility in dealing with problems of cultural differences involves competence in two aspects: (1) the participant's competence to make flexible adjustment to his communicative behavior according to the mutual cultural background so as to achieve the desired result; (2) the competence to deal with the communicative conflict resulting from the cultural differences.

In the cross-cultural communication, a likely situation is that how the two sides can make sure of the smooth going-on of the communication since they both come from non-English-speaking countries with different rules of social communication in their cultures though they both take English as communicative tool. The ideal situation is that with high sensitivity and tolerance to the cultural differences both sides try to understand the other's communicative rules and draw to each other as close as possible so as to achieve the final success of communication through continuous consultation and adjustment. The communicative rule involved in the cross-cultural communication is different from not only the communicative rule in the culture of target language but also in the participant's native language. We may call it inter-cultural communicative rule (Wen Qiufang, 2000). The difference between it and the general communicative rule lies in the fact that it is decided by the two sides' continuous consultation and adjustment and comes into being during the process of communication instead of before it. Consequently, the participants need to have great competence in dealing with unexpected communicative conflicts.

Flexibility in dealing with problems of cultural differences also involves the competence to deal with the communicative conflict resulting from cultural differences. During the process of cross-cultural communication, the two sides tend to meet with communication barriers. There are two main reasons for it: one is that their foreign language level can't meet the needs of communication, which is called linguistic communication barrier; the other is that cultural differences lead to their contradictions called cultural communication barrier. Some strategy and skills are necessary in dealing with the cultural communication barrier. Above all, the participant should be good at making clear his puzzlement over the opposite culture in verbal communication and understanding the other's cultural customs. At the same time, he should explain to his counterpart the behavioral norm in his native culture. Only in this way can the conflict be solved quickly. Of course, if he cannot express what he wants to say clearly for his poor foreign language, it is useless in spite of the good wish to solve the communication conflict. Therefore, cross-cultural competence should be based on linguistic competence. In other words, the former is only illusory separated from the latter.

\section{Relationship among Components of Cross-cultural Competence}

The three components of cross-cultural competence do not exist in isolation and there is a hierarchical relation between them as shown in Figure 6. Tolerance towards cultural differences lies in the middle of the hierarchy with sensitivity to cultural differences at the bottom and flexibility in dealing with problems of cultural differences at the top. Their logical relationship must not be reversed, which is easy to explain. If the students have no competence to sense cultural differences, it is impossible to come to "tolerance" and "flexibility". Therefore, "tolerance" is not the natural outcome of "sensitivity" and deserves special training. In the same way, sensitivity and tolerance to cultural differences cannot make sure the students can deal with problems in cultural communication flexibly, because special techniques and skills are needed here.

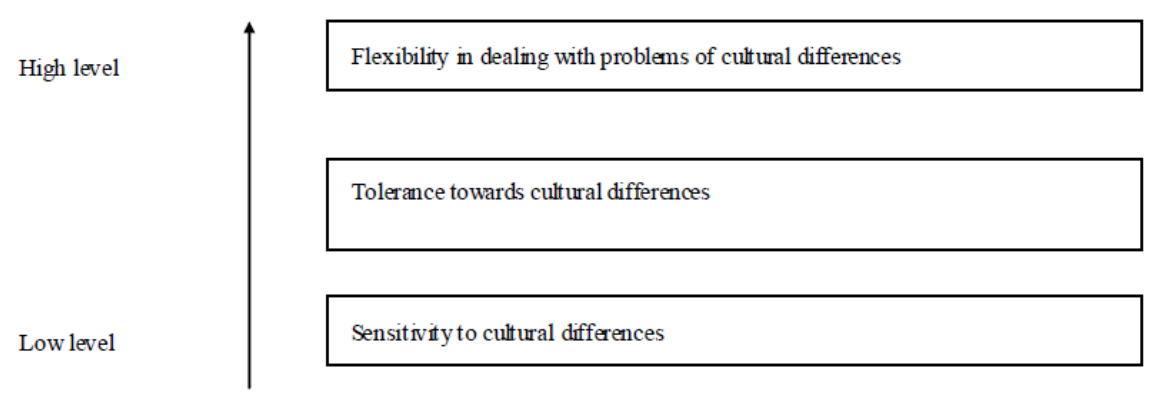

Figure 6 Inner hierarchical order of cross-cultural competence 
Development of cross-cultural competence should be carried on step by step from the low level to the high. That is to say, in the process of developing the students' cross-cultural competence, we should begin with improving their level of sensing cultural differences in order to train their sensitivity to cultural differences; then have them take a correct attitude towards cultural difference so as to make them understand and respect each other's culture; finally train their techniques and skills to deal with cultural differences. The above-mentioned three tasks should be combined together in teaching to develop their cross-cultural competence by means of spiral circulation.

\section{SUMMARY AND IMPLICATIONS}

In view of the discussion above, we suggest a course favorable to develop cross-cultural competence be added to the current curriculum as far as possible. It is different from not only the traditional course An Outline Introduction of Britain and America but A Survey of English-speaking Countries with enlarged contents. It aims at introducing the general trend and characteristics of worldwide cultural differences objectively and providing rational explanation of tolerance and respect for foreign cultures instead of focusing on some country's culture. Teachers will make analyses and discussion on some cases and encourage students to find solutions to the problems. We may take the method of Project \& Presentation Teaching and Learning with students acting as the center (Luo Jing, 2004). Here Project means project research. Centering on the nature of the course and teaching contents combined with the knowledge points students should grasp as well as their interest, teachers design and choose topics together with students; make research and investigation in extracurricular time by means of making questionnaire and interview, consulting materials and looking up what are needed on the internet; then writer English reports after analyzing the materials collected. Presentation means students state their summary, deliver report, perform or display objects as well as answering other students' questions within the fixed time in class after they complete their Project. Based on the teaching plan in the process of teaching, it can be carried on by (1) incorporating it in intensive reading and listening teaching; (2) penetrating it in CET-4 and CET-6 guidance; (3) instilling it by giving thematic lectures and distributing extracurricular materials (Li Xue \&Wang Simei, 2001).

\section{REFERENCES}

[1] Bachman, L. F. (1990). "Fundamental considerations in language testing". Oxford: Oxford University Press.

[2] Canale, M. and Swain, M. (1980). 'Theoretical bases of communicative approaches to second language teaching and testing'. Applied Linguistics 1.

[3] Coulthard, M.( 1985). (2 ${ }^{\text {nd }}$ edition) "An introduction to discourse analysis". London: Longman.

[4] Hymes, D. (1972). "On communicative competence". In J. B. Pride and J. Holmes (eds) Sociolinguistics. Harmondsworth: Penguin.

[5] Hymes, D.( 1977). "Foundations in sociolinguistics". London: Tavistock Publications.

[6] Li Xue, Wang Simei. (2001). "On importance of culture teaching in foreign language teaching". In Gao Yuan. Reform and Discovery in Foreign Language Teaching. Neijing: Beihang University Press.

[7] Luo Jing. (2004). "A New Teaching Model Applied to the Classroom Teaching of A Survey of English-speaking Countries---Project and Presentation". Journal of the Foreign Language World, (3):14-17.

[8] Richards, J. C., J. Platt, and H. Platt. (2000). "Longman dictionary of language teaching and applied linguistics". Beijing: Foreign language teaching and research.

[9] Stern, H. H. (1999). "Fundamental concepts of language teaching”. Shanghai: Shanghai foreign language education press.

[10] Wen Qiufang. (2000). “Testing \& Teaching Spoken English”. Shanghai: Shanghai Foreign Language Education Press.

Yanbin Qin was born in Shandong, China in 1969. He received his M.A. degree in Foreign Linguistics and Applied Linguistics, Qufu Normal University, China in 1999.

He is currently a professor in Department of Fundamental Courses, Zhenjiang Watercraft College, Zhenjiang, China. His research interests mainly include Applied Linguistics and Translation Theory and Practice. 